\title{
Intragenic repeat expansions control yeast chronological aging
}

Benjamin P Barré1*, Johan Hallin¹, Jia-Xing Yue ${ }^{1}$, Karl Persson², Ekaterina Mikhalev ${ }^{3}$, Agurtzane Irizar $^{1}$, Dawn Thompson ${ }^{3}$, Mikael Molin ${ }^{4}$, Jonas Warringer ${ }^{2}$ and Gianni Liti ${ }^{*}$

1'Université Côte d'Azur, CNRS, INSERM, IRCAN, Nice, France; ${ }^{2}$ Department of Chemistry and Molecular Biology, University of Gothenburg, Gothenburg, Sweden; ${ }^{3}$ Ginkgo Bioworks Inc. Boston, MA 02210, USA; ${ }^{4}$ Department of Biology and Biological engineering, Chalmers University of Technology, Gothenburg, Sweden

*Correspondence should be addressed to B.B. (byngeamain@gmail.com) or to G.L. (gianni.liti@unice.fr).

\section{ABSTRACT}

Aging varies among individuals due to both genetics and environment but the underlying molecular mechanisms remain largely unknown. Using a highly recombined Saccharomyces cerevisiae population, we found 30 distinct Quantitative Trait Loci (QTLs) that control chronological life span (CLS) in calorie rich and calorie restricted environments, and under rapamycin exposure. Calorie restriction and rapamycin extended life span in virtually all genotypes, but through different genetic variants. We tracked the two major QTLs to massive expansions of intragenic tandem repeats in the cell wall glycoproteins FLO11 and HPF1, which caused a dramatic life span shortening. Life span impairment by $\mathrm{N}$-terminal HPF1 repeat expansion was partially buffered by rapamycin but not by calorie restriction. The HPF1 repeat expansion shifted yeast cells from a sedentary to a buoyant state, thereby increasing their exposure to surrounding oxygen. The higher oxygenation perturbed methionine, lipid, and purine metabolism, which likely explains the life span shortening. We conclude that fast evolving intragenic repeat expansions can fundamentally change the relationship between cells and their environment with profound effects on cellular life style and longevity. 


\section{INTRODUCTION}

Aging is a progressive decline in biological functions occurring in almost all living organisms that ultimately leads to death (Finch 1990; Jones et al. 2014). The first life span regulating genes were identified in the beginning of the 90s (Johnson 1990; Kenyon et al. 1993; Sun et al. 1994). Today hundreds have been uncovered (Kenyon 2010), although most are of small effect and few explain aging variation between individuals. Besides genetics, environmental factors, such as calorie restriction (CR) (Colman et al. 2009; Jiang 2000; Klass 1977; Pletcher et al. 2002; Weindruch et al. 1986), reduced oxygen exposure (Leiser et al. 2013; Rascon and Harrison 2010), and low temperature (Conti et al. 2006; Leiser, Begun, and Kaeberlein 2011; Sestini, Carlson, and Allsopp 1991), extend longevity. How genetics and environment interact to control variation in life span and by which mechanisms remains poorly understood. The beneficial effect of calorie restriction on longevity in organisms ranging from yeast (Lin, Defossez, and Guarente 2000) to primates (Mattison et al. 2017) has been known for $>80$ years (McCay, Crowell, and Maynard 1935) and is still the most successful intervention to delay aging, although its impact on life span has sometimes been disputed (Liao et al. 2010; Schleit et al. 2013). Cellular mediation of CR is at least in part occurring through nutrient sensitive signalling networks, including the insulin/IGF-1, mTOR (target of rapamycin), CAMP-PKA and AMPK pathways. These are held to regulate life span by controlling stress responses, mitochondrial respiration, redox homeostasis, genome stability, autophagy, energy and fat metabolism (Alvers et al. 2009; Hansen et al. 2008; Madia et al. 2008; Molin et al. 2011; Schulz et al. 2007; Wei et al. 2008; Weinberger et al. 2007; Yuan et al. 2012). Pharmaceutical control of some of these pathways can extend longevity in model organisms. Rapamycin, a clinically approved TOR inhibitor (Eisenberg et al. 2009; De Haes et al. 2014; Harrison et al. 2009; Martin-Montalvo et al. 2013), extends life span by mimicking CR (Blagosklonny 2010), but undesirable side effects in humans restrict its usage (Kaeberlein 2014).

The budding yeast $S$. cerevisiae has been pivotal in elucidating mechanisms regulating aging. Yeast aging can be studied through two approaches: replicative life span (RLS) and chronological life span 
bioRxiv preprint doi: https://doi.org/10,1101/653006; this version posted June 22, 2019. The copyright holder for this preprint (which was not certified by peer review) is the author/funder, who has granted bioRxiv a license to display the preprint in perpetuity. It is made available under aCC-BY-NC-ND 4.0 International license.

(CLS). Replicative life span is the number of mitotic divisions before senescence and is used as a paradigm to study aging of proliferative tissues, such as stem cells (Mortimer and Johnston 1959; Steinkraus, Kaeberlein, and Kennedy 2008). Chronological lifespan is the time yeasts survive in nonproliferative conditions and models the aging of post-mitotic cells, such as neurons (Longo et al. 2012; Longo, Gralla, and Valentine 1996). Hundreds of genes whose disruption affect the CLS of lab domesticated yeast in calorie rich (Fabrizio et al. 2010; Garay et al. 2014; Powers et al. 2006) and calorie-restricted (Matecic et al. 2010) environments have been identified. However, most studies relied on artificial gene deletions and were performed in lab domesticated strains, which are highly atypical (Warringer et al. 2011), maintained as haploids rather than diploids (Peter et al. 2018), carry auxotrophies that alter life span (Boer, Amini, and Botstein 2008; Gomes et al. 2007), and have never been exposed to natural selection. Thus, genetic variants that regulate natural life span variation are still largely unknown. Crosses between natural yeast strains have the potential to uncover these variants (Brem 2002; Steinmetz et al. 2002), but remain poorly explored. Previous work linked natural polymorphisms in the ribosomal DNA and in the sirtuin SIR2 (Kwan et al. 2013; Stumpferl et al. 2012), as well as telomere maintenance (Kwan et al. 2011) and serine biosynthesis (Jung et al. 2018) to life span variation. Lack of genetic diversity, mapping resolution and power has prevented more exhaustive exploration.

We unravelled the genetic basis of CLS variation using advanced intercrosses between two natural S. cerevisiae isolates with very different life spans. We measured CLS in calorie rich and calorie restricted media, and under rapamycin treatment. We mapped 30 unique QTLs of which the two major were explained by massive intragenic tandem repeat expansions in the cell wall glycoproteins FLO11 and HPF1 that dramatically shortened life span. Serine/threonine repeat expansions close to the HPF1 N-terminus shifted cells from a sedentary to a buoyant life style, thereby increasing exposure to oxygen and perturbing methionine, lipid and purine homeostasis. Interestingly, the downstream effects of buoyancy were partially recovered by rapamycin treatment, suggesting that they can be targeted by TORC1 repression. 


\section{RESULTS}

\section{Calorie restriction and rapamycin extend life span through different genetic variants}

We crossed a long-lived North American (NA) oak tree bark strain (YPS128) with a short-lived West African (WA) palm wine strain (DBVPG6044) which differ at $0.53 \%$ of nucleotide sites (Liti et al. 2009; Parts et al. 2011). A pool of F12 segregants of opposite mating types were then mated to generate 1056 diploids with hybrid, phased genomes, termed Phased Outbred Lines (POLs) (Hallin et al. 2016). POLs were individually cultivated in calorie rich (synthetic dextrose complete, SDC), calorie restricted $(\mathrm{CR})$, or rapamycin supplemented $(\mathrm{RM})$ environments for the whole experiment, and viability was measured by high throughput flow cytometry at 7,21 , and 35 days after media exhaustion. A total of 52466 genetic markers were called and used to run a genome-wide linkage analysis.

We found a remarkable lifespan diversity (Fig. 1A and table S3), with survival rates ranging from 6 to $97 \%$ already after 7 days in SDC (47\% mean viability). Calorie restriction ( $86 \%$ mean viability at day 7) and RM (83\% mean viability at day 7) sharply extended life spans of all genotypes (with a single exception in RM) (Fig. 1A and S1A). Life span was fairly correlated across environments (Pearson's $r=0.62$ for SDC vs CR, 0.53 for SDC vs RM; Fig. 1B) implying that CLS is mainly regulated by shared genetic effects across environments. Nevertheless, the more modest correlation between CR and RM (Pearson's $r=0.43$; Fig. 1C) suggested that partially distinct molecular mechanisms controlled their life span extension effect.

We found a total of 30 unique QTLs associated with chronological aging (Fig. 1D, S1B) that explained up to $40 \%$ of life span variation (Table S4). QTLs were mostly private to one environment and only three were detected in all (Fig. 1E). Two of these, located on chrlX and chrXV, were strikingly stronger than others and explained up to $\sim 30 \%$ and $\sim 20 \%$ of life span variation respectively (Table S4). Although both major QTLs were ubiquitous, the chrXV QTL was partially masked by RM treatment, whereas the chrIX QTL only became significant at advanced age (days 21 and 35) (table S4 and Fig. 1D and S1B). Most of the remaining QTLs were time and environment dependent and explained much less (mean: $\sim 3 \%$ ) of the life span variation (Table S4). Thus, CLS was largely determined by a 
bioRxiv preprint doi: https://doi.org/10.1101/653006; this version posted June 22, 2019. The copyright holder for this preprint (which was

not certified by peer review) is the author/funder, who has granted bioRxiv a license to display the preprint in perpetuity. It is made available under aCC-BY-NC-ND 4.0 International license.

few, very strong QTLs that were shared across calorie rich and calorie restricted environments.

Chronological life span was then fine-tuned by mechanisms private to each environment; although

the conservative threshold for calling QTLs may lead us to somewhat underestimate the shared QTLs. 

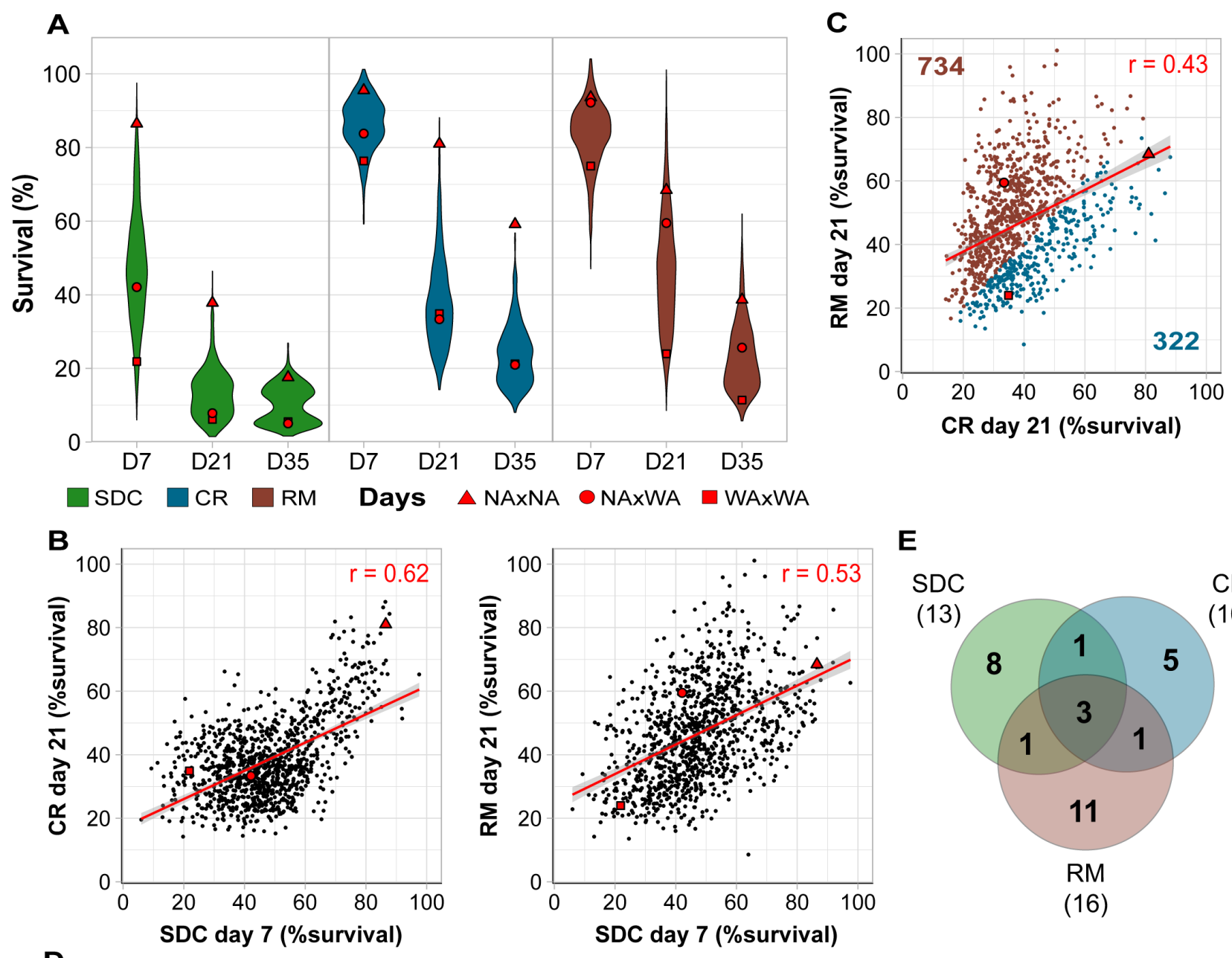

D
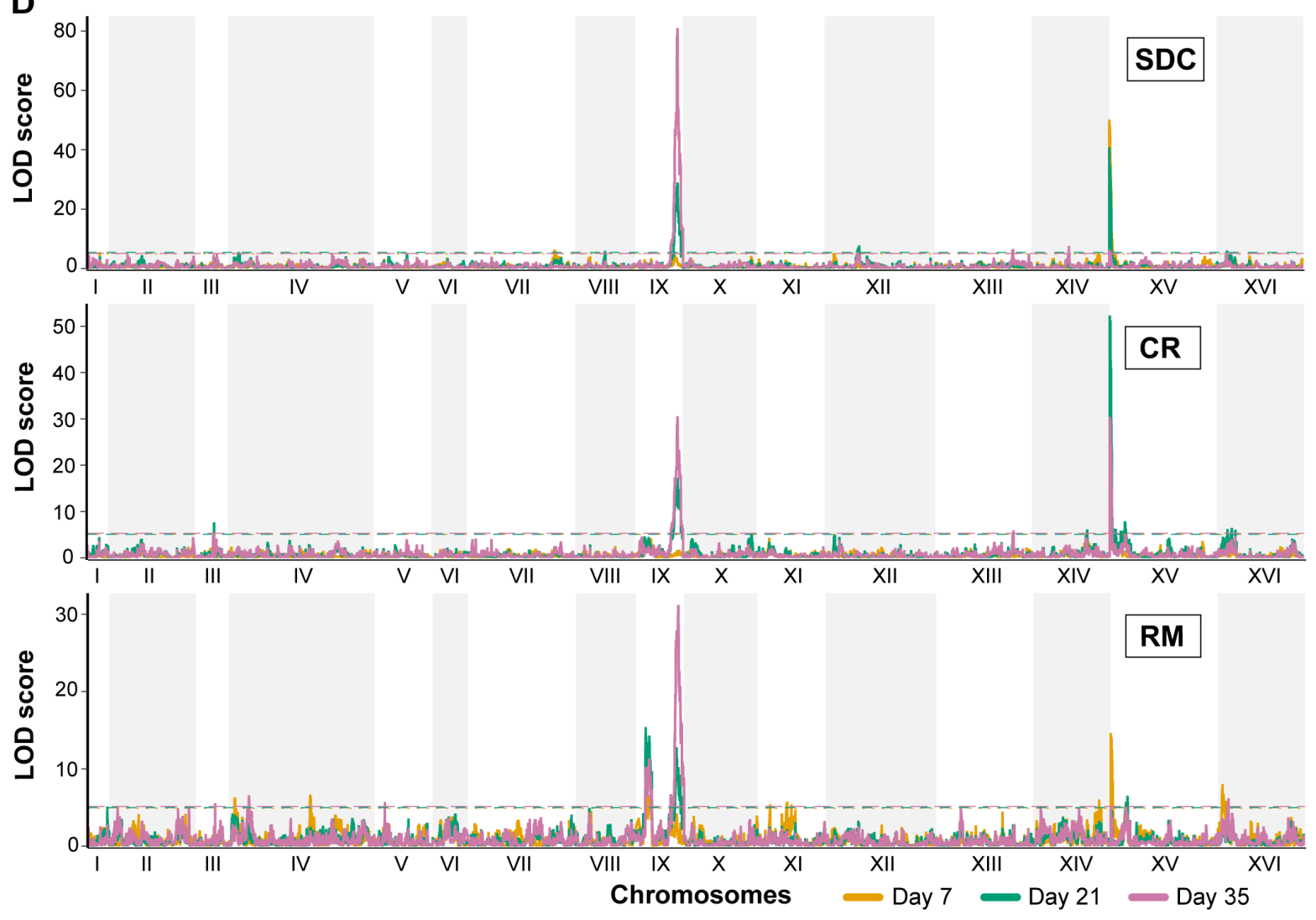

Fig 1. Calorie restriction and rapamycin extend life span through different genetic variants 
Fig 1. Calorie restriction and rapamycin extend life span through different genetic variants

Chronological life span of 1056 diploid segregant lineages from an F12 NA/WA advanced intercross. CLS was measured by counting viable cells (\%) 7, 21 and 35 days after entry into quiescence, following growth in calorie sufficient (SDC), restricted $(\mathrm{CR})$ and rapamycin $(\mathrm{RM})$ media. Red: Founder homozygote parents (NA/NA, WAWA) and their F1 hybrid (NAWA). (A) CLS distributions. (B) Comparing CLS across environments and time points. Red line: linear regression, with 95\% confidence interval. (C) CLS distributions. Numbers: lineages living longer in one environment. Blue: living longer in CR, brown: living longer in RM. (D) Linkage analysis of CLS. Panels: calorie rich (top), restricted (middle) and rapamycin (bottom) media. Line colour: 7 (yellow), 21 (green) and 35 (purple) days after entry into quiescence. $y$-axis: LOD score, $x$ axis: genome position. Dashed lines: significance QTL $(a=0.05)$. (E) QTLs private to and shared between environments. Numbers in parentheses: total QTLs per environment.

\section{Natural variations in cell wall glycoproteins HPF1 and FLO11 control chronological life} span

The two major QTLs peaked within FLO11 (chrIX) and HPF1 (chrXV). Both encode secreted cell wall glycoproteins with no known connections to life span. Hpf1p is functionally uncharacterized, while Flo11p regulates cell adhesion, pseudohyphae and biofilm formation (Douglas et al. 2007; Guo et al. 2000; Váchová et al. 2011). We found shorter life span for WA-FLO11 and HPF1 compared to NA homozygotes, with the WA short life span alleles being completely dominant (Fig. 2A). We validated these effects in a reciprocal hemizygosity assay (Steinmetz et al. 2002) (Fig. 2B and methods); a NAWWA hybrid deleted for the WA-HPF1 allele lived 70\% longer, regardless of the presence of NAHPF1 (Fig. 2C). Life span extension by rapamycin, but not by calorie restriction, rescued the WAHPF1 shortening, consistent with the QTL being exclusively weaker in rapamycin (Fig. 2C and 1D). The WA-FLO11 also shortened life span but to a lesser extent compared to expectations from the QTL strength, perhaps due to either linkage or epistasis with other variants. As for HPF1, removing the WA-FLO11 or both the WA and NA-FLO11 alleles extended life span, while removing the NAFLO11 had no effect (Fig. 2D). The negative effect of WA-FLO11 increased with age and was not rescued by rapamycin, again as expected (Fig. 2D and 1D). Removing both alleles of either HPF1 or FLO11 extended the life span of WAMA but not NA/NA homozygote, and failed to affect the domesticated reference strain, S288C (Fig. S2). 
A

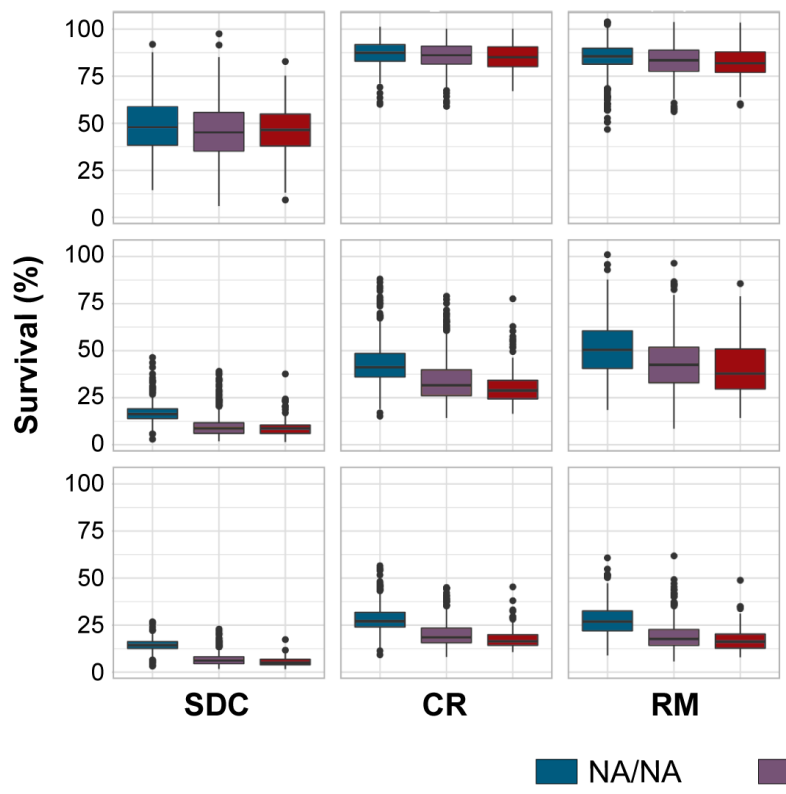

chr IX - 394371
B

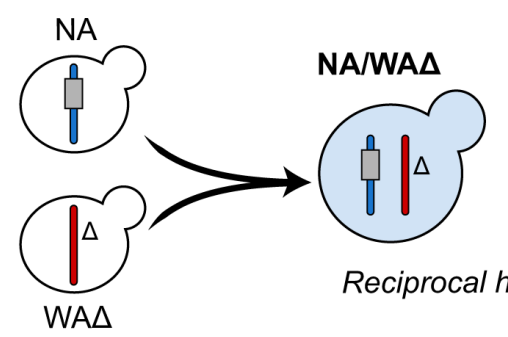

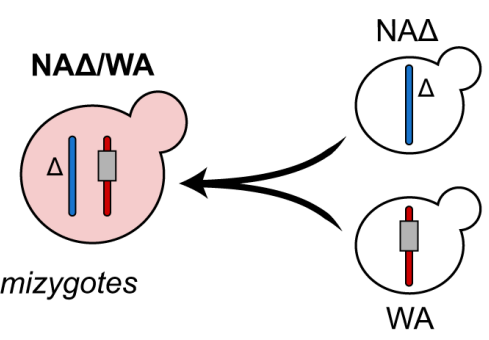

C
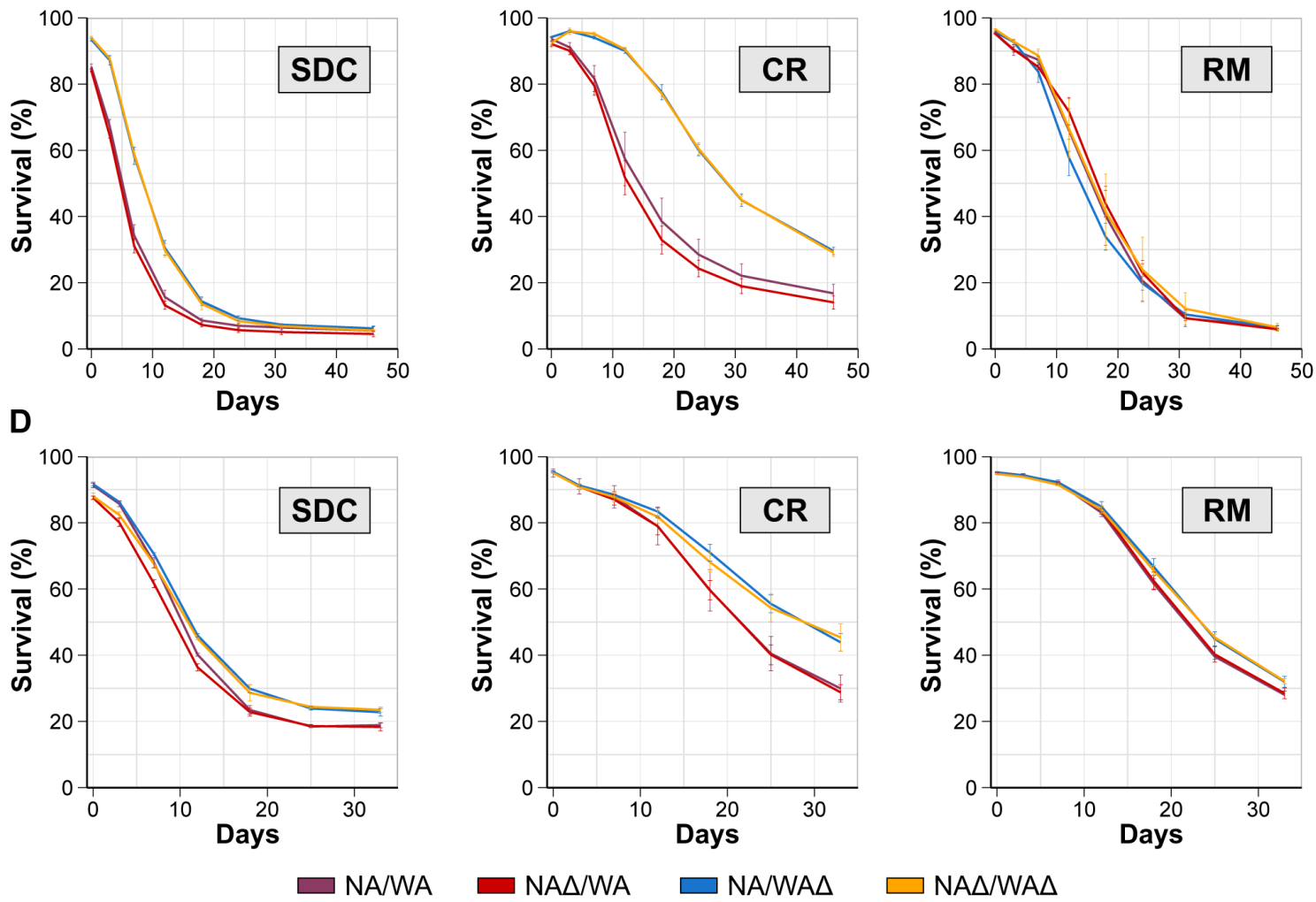

Fig 2. Natural variations in cell wall glycoproteins HPF1 and FLO11 control chronological life span 
Fig 2. Natural variations in cell wall glycoproteins HPF1 and FLO11 control chronological life span

(A) Chronological life span of the 1056 segregant lineages from the F12 NAWA advanced intercross. Lineages were separated according to genotype at the markers with highest LOD score in each of the two major QTLs: 394,381 kb in chromosome IX (in FLO11) and 33,217 kb in chromosome XV (in HPF1). (B) Schematic representation of the NA/WA reciprocal hemizygosity design used to validate the CLS effect of the HPF1 and FLO11 WA alleles. Colour: NA (blue) and WA (red) chromosomes. Grey rectangle: candidate gene (HPF1, FLO11). $\triangle$ : gene deletion. (C) Reciprocal hemizygosity. CLS of NA/WA hemizygotes for NA (blue; WA $\triangle$ ) and WA (red; NA $\triangle$ ) HPF1, heterozygote for HPF1 (purple; NA/WA) and lacking HPF1 (yellow; NA $\triangle \mathrm{WA} \triangle$ ). (D) As in C) but for FLO11.

\section{Massive intragenic tandem repeat expansions within FLO11 and HPF1 shorten life span}

Remarkably, FLO11 and HPF1 both carry intragenic tandem repeats that are massively expanded in the WA allele. WA-HPF1 is twice as long (6006 vs. 3033bp) and WA-FLO11 is $10 \%$ longer (4014 vs. 3654bp) than their NA counterparts (Fig. 3A and S3A). Repeat motifs were between 21 and 71 amino acids long and mainly composed of threonine and serine, as reported for alleles of other cell wall proteins (Verstrepen and Klis 2006) (Fig. 3A). The partial motif degeneration in these repeat motifs prevented pinpointing their exact patterns and boundaries for both HPF1 and FLO11. Such repeat expansion in WA alleles is gene specific; of 26 genes containing very long tandem repeats (Verstrepen et al. 2005) only HPF1 was massively expanded in WA relative to six other strains for which complete genome assemblies exists (Yue et al. 2017) (Fig. 3B).

We hypothesized that the WA-HPF1 massive repeat expansions explained the life span shortening and tested this by swapping HPF1 alleles in the F1 NAWA hybrid. We removed WA-HPF1, while the remaining NA allele was engineered to contain specific segments of the WA allele (see methods). Swapped segments corresponded to $\mathrm{N}$ - and C-terminal blocks of tandem repeats, and to the highly polymorphic internal unique domain (Fig. $3 \mathrm{~A}$ and $3 \mathrm{C}$ ). Substituting the C-terminal repeats or the internal domain of NA-HPF1 with its WA counterpart did not shorten CLS, but replacing the Nterminal repeats shortened CLS as much as the native WA allele (Fig. 3C). Likewise, inserting the WA N-terminal repeats into a NA homozygote diploid dramatically shortened life span (Fig. S3B), 
bioRxiv preprint doi: https://doi.org/10.1101/653006; this version posted June 22, 2019. The copyright holder for this preprint (which was

not certified by peer review) is the author/funder, who has granted bioRxiv a license to display the preprint in perpetuity. It is made available under aCC-BY-NC-ND 4.0 International license.

while inserting the NA N-terminal repeats into a WA homozygote diploid extended its life span to a comparable extent (Fig. S3C). 


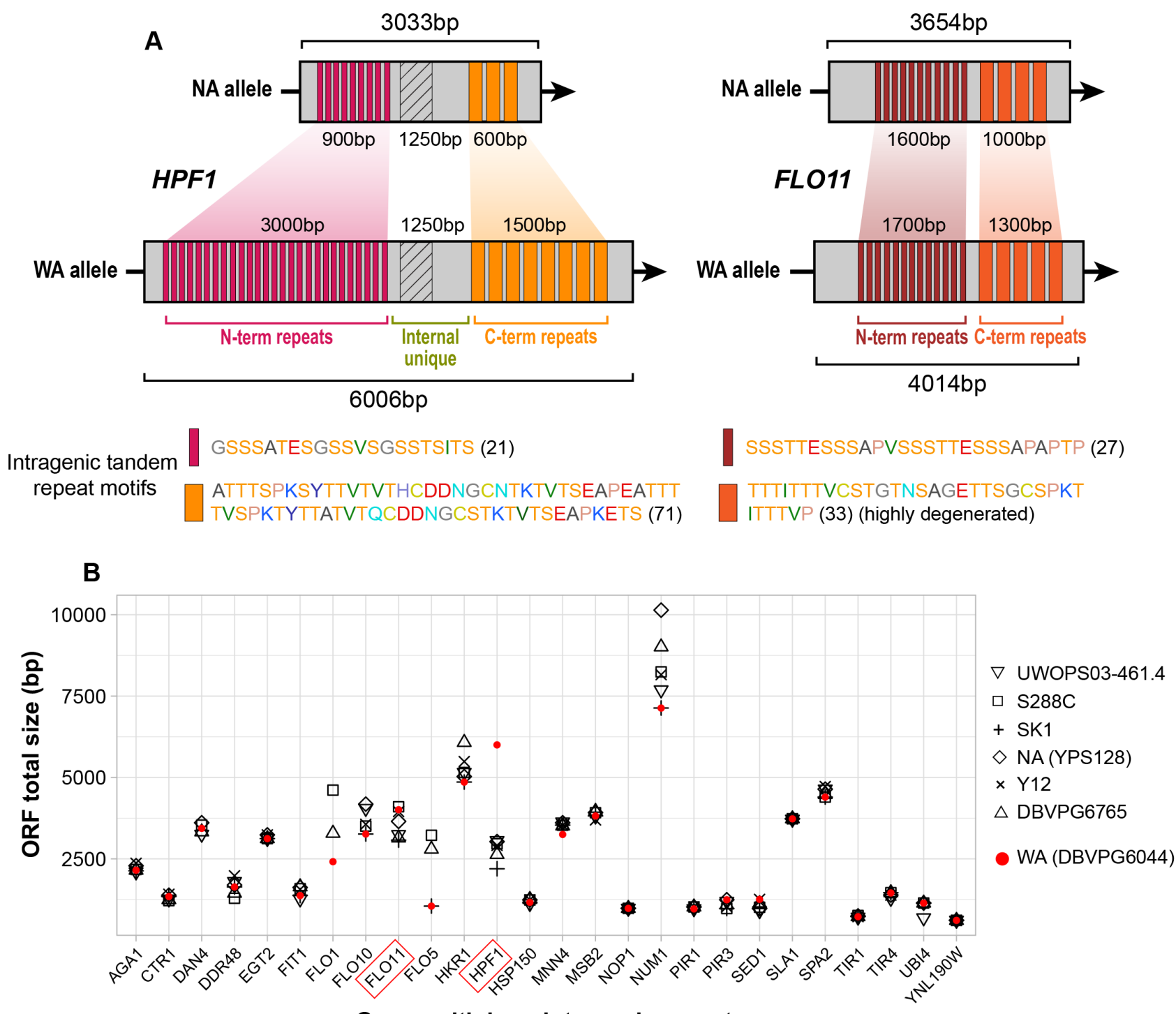

\section{Genes with long intragenic repeats}

C

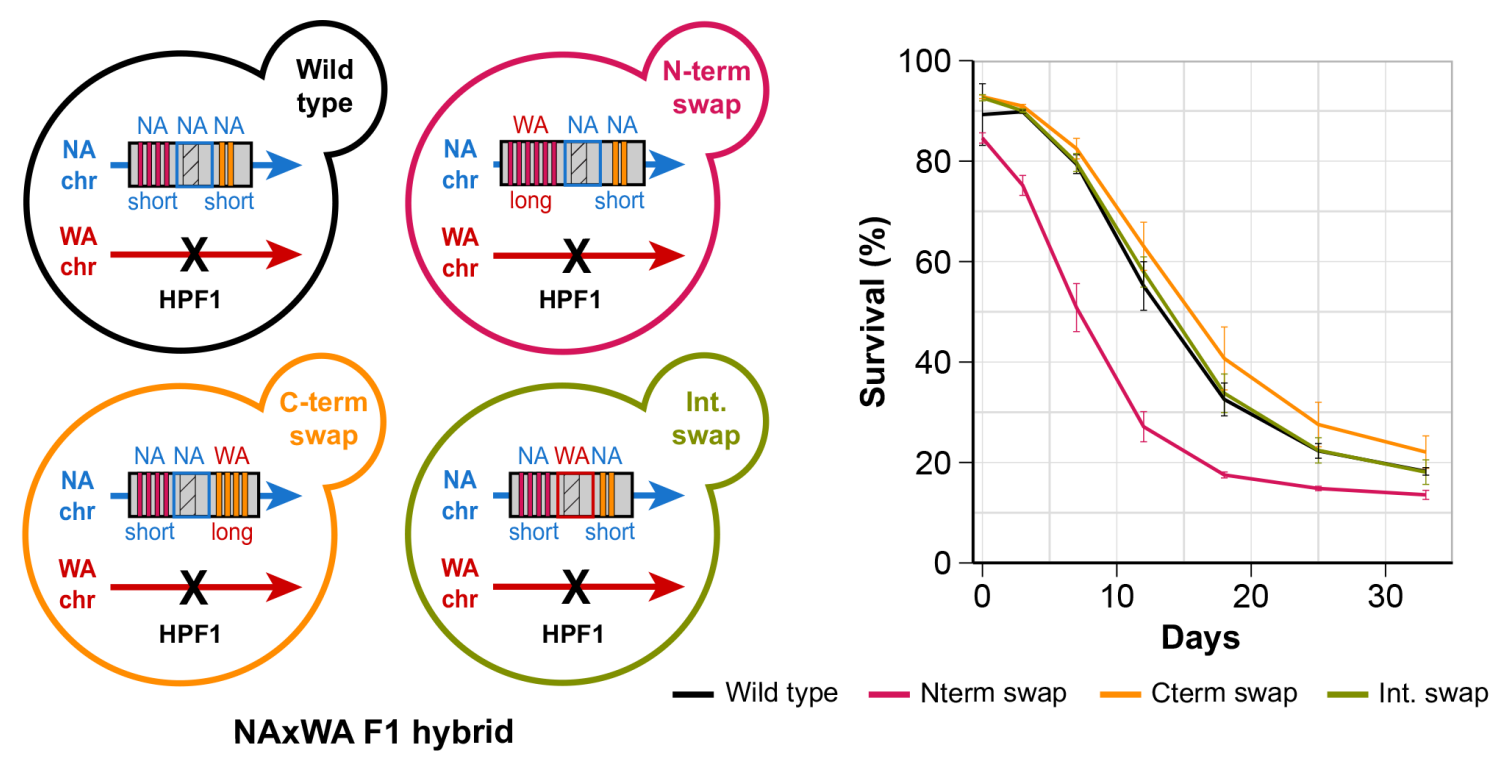

Fig 3. Massive intragenic tandem repeat expansions within FLO11 and HPF1 shorten life span 


\section{Fig 3. Massive intragenic tandem repeat expansions within FLO11 and HPF1 shorten life span}

(A) Schematic representation of the intragenic repeats (coloured rectangles) in HPF1 and FLO11 in NA and WA. Hatched rectangle: a HPF1 internal unique region with high sequence variation between NA and WA alleles. Zoom-in: repeat motifs. Amino acids are colored according to the RasMol nomenclature. Numbers = motif size (amino acids). (B) Size variation of genes containing long intragenic repeats in seven diverged S. cerevisiae strains (Verstrepen et al. 2005; Yue et al. 2017). Diamonds: North American. Red circles: West African. (C) Left panel: Design of allele swaps of HPF1 segments in the NAWA F1 hybrid. The WA-HPF1 allele was deleted (black cross), while the NA-HPF1 was kept unchanged (wildtype), or a segment was replaced by the corresponding WA-HPF1 segment. N-term: N-terminal repeats, C-term: C-terminal repeats, Int: internal unique region. Right panel: CLS for allele swapped constructs.

\section{Buoyancy triggered by HPF1 N-terminal repeat expansions shortens life span}

Intriguingly, NA/WA hybrids carrying only the WA-HPF1 became buoyant during exponential growth, i.e. they shifted to a free-floating life style. Following entry into stationary phase, cells sedimented again, returning to a sedentary life style (Fig. 4A). We tracked this life style shift to the WA-HPF1 Nterminal repeat expansion, by showing that it induces flotation (Fig. 4B). To probe whether buoyancy per se shortened lifespan, we repeated the CLS assay in intensely shaken flasks rather than in static 96 well-plates. Because intense shaking forces all yeast cells to remain in suspension, we postulated that it would eliminate the HPF1 life span shortening only if it was due to buoyancy. In line with this assumption, we found that buoyancy enforced by shaking reduced life span dramatically and completely negated the effect of HPF1 allelic variation on life span (Fig. 4C). Shorter life span in shaking cultures has previously been explained as a result of higher exposure to oxygen (Fabrizio et al. 2003; Longo et al. 1999). Thus, by promoting cellular buoyancy in static cultures, HPF1 exposes cells to higher oxygen levels and shortens life span, without affecting medium acidity and with no effect of Hpf1p secretion to the medium (Fig. S4A and S4B). Complete HPF1 removal in the WA homozygote nullified cell buoyancy and increased CLS, whereas it neither affected buoyancy nor life span in the NA homozygote (Fig. 4D). We conclude that buoyancy shortens life span and that HPF1 controls life span by shifting cells between buoyant and sedentary life styles. 

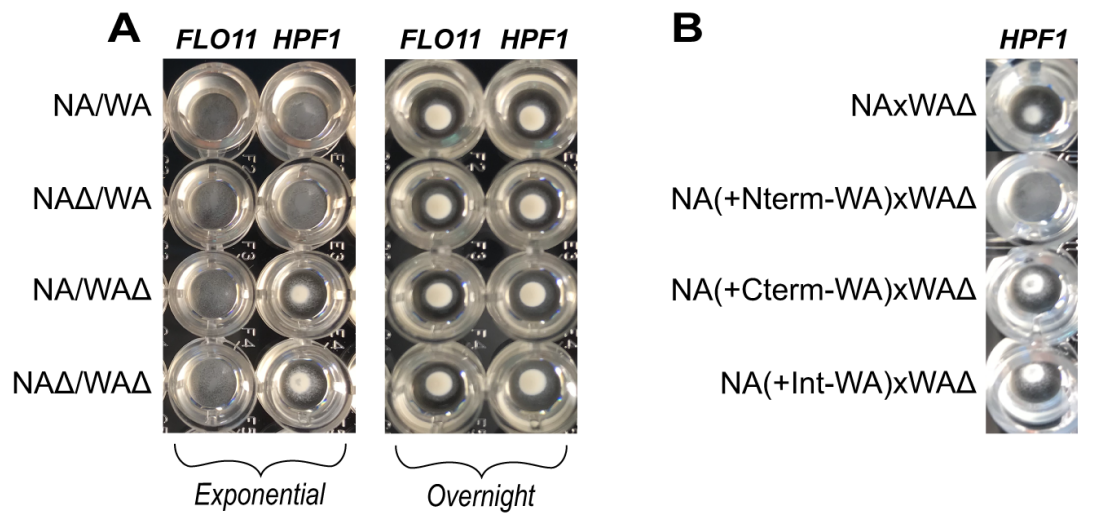

D
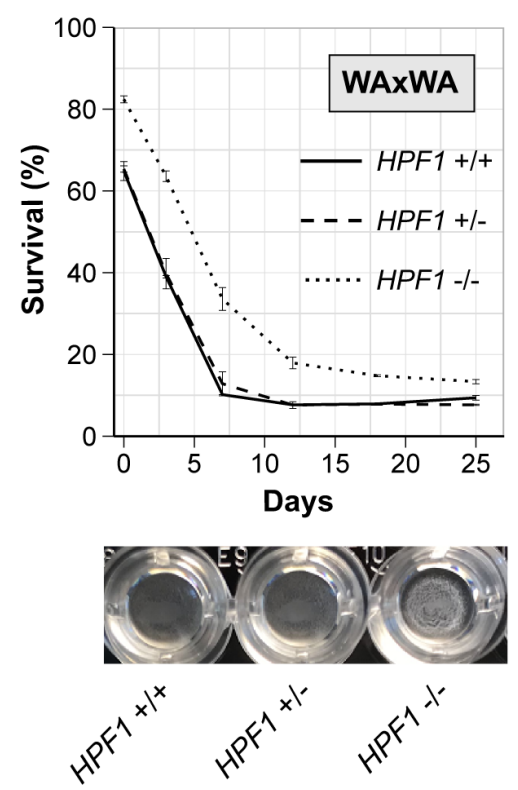
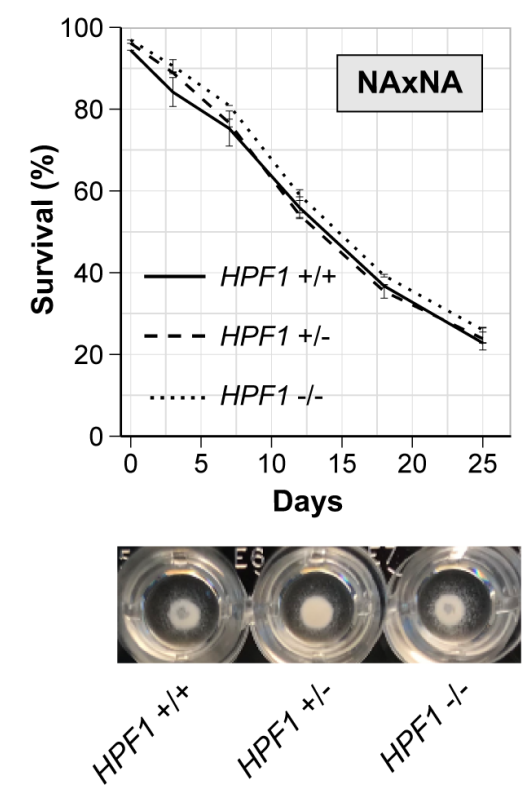

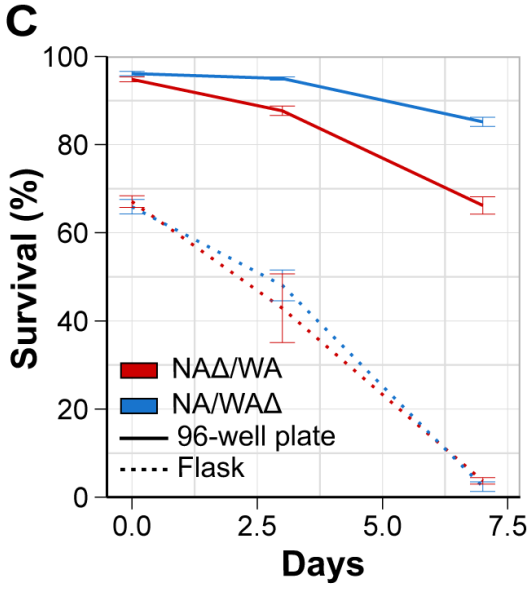

Fig 4. Buoyancy triggered by HPF1 N-terminal repeat expansions shortens life span

\section{Fig 4. Buoyancy triggered by HPF1 $\mathrm{N}$-terminal repeat expansions shortens life span}

(A-B) Buoyancy of cells cultivated for 7 hours (exponential phase) or overnight in calorie rich (SDC) medium in a 96-well plate. A) HPF1 and FLO1 hemizygotes. B) HPF1 allele swaps (see Fig 3C). (C) Comparing CLS of HPF1 hemizygote cells cultivated in shake flasks and 96-well plates. Shake flasks had a 5:1 volume/medium ratio and were shaken at 220rpm. 96-well plates were filled with $200 \mu \mathrm{L}$ medium, with no shaking. (D) CLS (top panel) and buoyancy (96 well plates; exponential phase) of WA and NA homozygotes with no (full line), 1 (dashed lines) or both copies (dotted lines) of HPF1 deleted in calorie rich medium (SDC). 
bioRxiv preprint doi: https://doi.org/10.1101/653006; this version posted June 22, 2019. The copyright holder for this preprint (which was

not certified by peer review) is the author/funder, who has granted bioRxiv a license to display the preprint in perpetuity. It is made available under aCC-BY-NC-ND 4.0 International license.

\section{HPF1 induced buoyancy reprograms methionine, lipid, and purine metabolism}

We hypothesized that meeting the oxygen challenge associated with HPF1 induced buoyancy would reprogram metabolism and gene expression. We therefore compared the transcriptomes of the two HPF1 reciprocal hemizygous hybrids, before (exponential growth) and after (7 days) the onset of aging (Table S5), with or without rapamycin exposure. During exponential growth, buoyancy and higher oxygen exposure induced by the WA-HPF1 only weakly affected transcript abundances (8 and 3 genes changing $>2$-fold in calorie rich and rapamycin media respectively, Fig. 5A and 5B). The known low oxygen responders TIR1 and ANB1 (Cohen et al. 2001; Lowry and Lieber 1986) were repressed by oxygen as expected. Five of the six transcripts induced by oxygenation encode methionine metabolic proteins (Fig. 5A), notably Mxr1p, reducing oxidised methionine. Induction of methionine reduction may signal increased methionine oxidation from ROS and explain the life span shortening. Rapamycin supplementation completely nullified the induction of methionine metabolism and reduction, despite cells being buoyant, potentially explaining why rapamycin prevents the WAHPF1 from shortening lifespan (Fig. 5A and S5A).

In sharp contrast to before the onset of aging, the oxygen exposure induced by buoyancy fundamentally (428 and 62 genes changing $>2$-fold, in calorie rich and rapamycin media) reprogrammed the transcriptome in aging cells (Fig. 5A and 5B). Above all, oxygenation broadly repressed lipid and purine biosynthesis transcripts (Fig. 5A), and in particular OLE1, a known hypoxia responder encoding the fatty acid desaturase (Kwast et al. 1999). Because lipid and purine metabolism are required for a long life (Arlia-Ciommo et al. 2018; Garay et al. 2014; Handee et al. 2016; Matecic et al. 2010), this repression may well contribute to the life span shortening of WAHPF1 cells. Overall, transcriptome changes implied that the life span shortening of WA-HPF1 cells may arise due to reduced lipid and purine biosynthesis as well as oxidation of free or protein bound methionine. 
bioRxiv preprint doi: https://doi.org/10.1101/653006; this version posted June 22, 2019. The copyright holder for this preprint (which was not certified by peer review) is the author/funder, who has granted bioRxiv a license to display the preprint in perpetuity. It is made available under aCC-BY-NC-ND 4.0 International license.
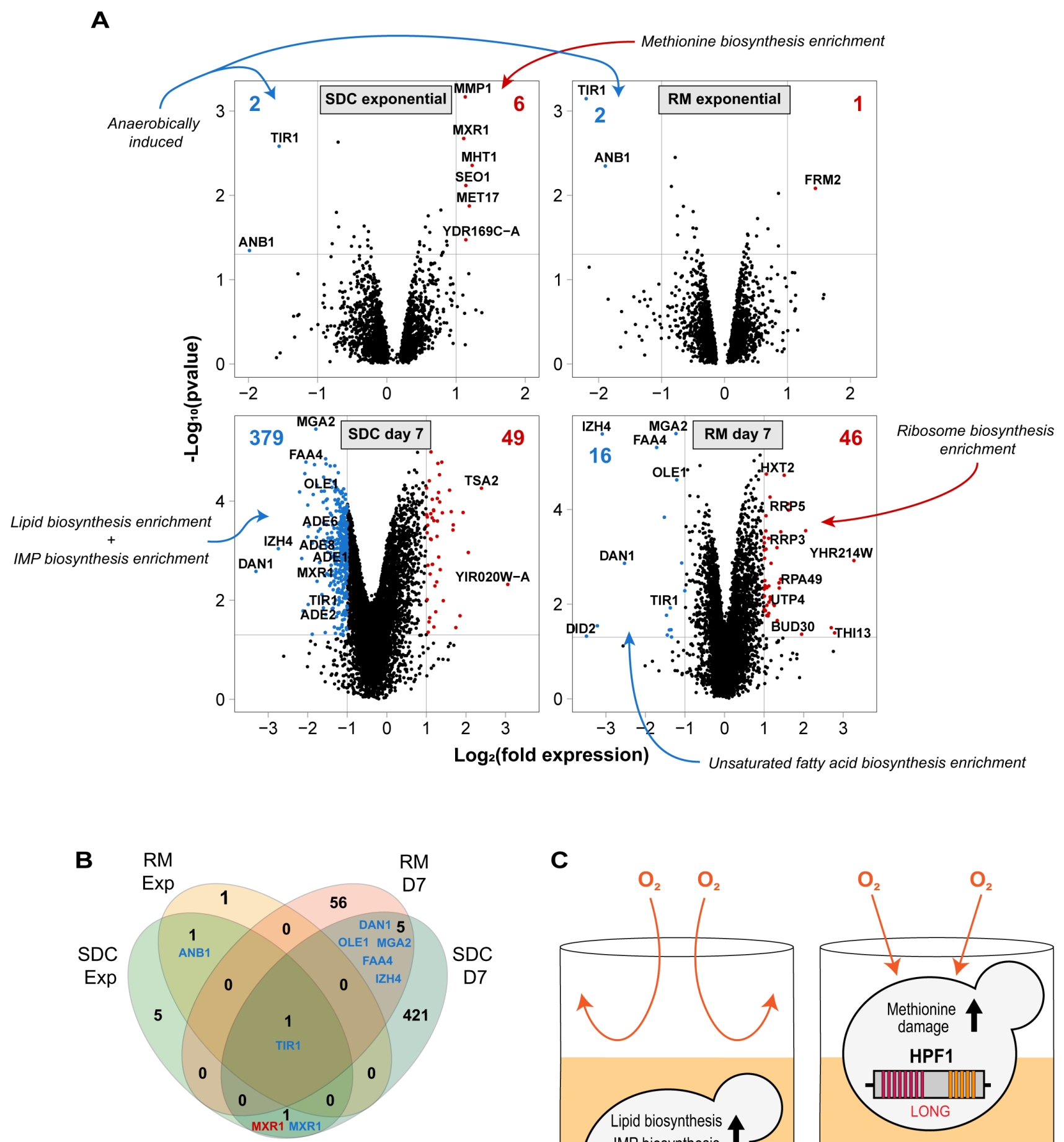

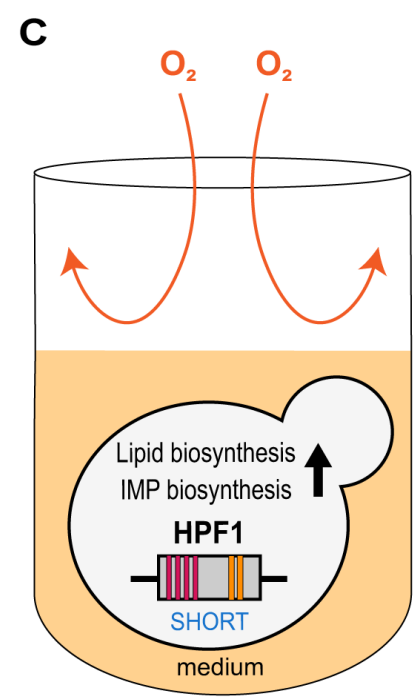

SEDIMENTATION

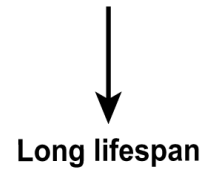

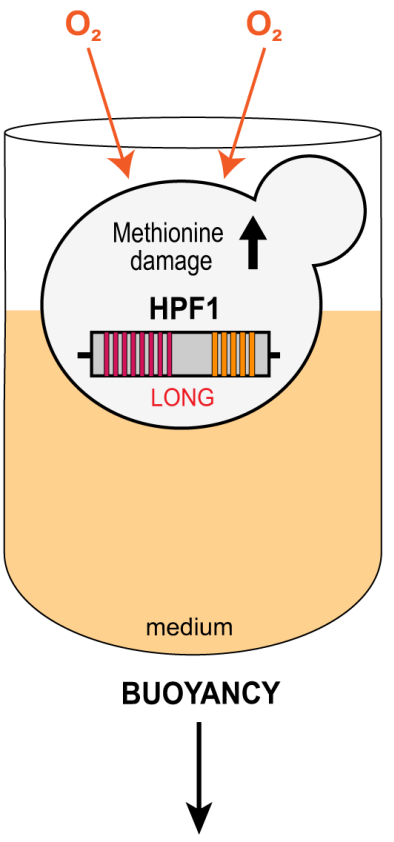

Short lifespan

Fig 5. HPF1 induced buoyancy reprograms methionine, lipid, and purine metabolism 


\section{Fig 5. HPF1 induced buoyancy reprograms methionine, lipid, and purine metabolism}

(A) Transcriptome changes induced by WA-HPF1 dependent buoyancy. NA/WA hybrids hemizygotes for WA or NA-HPF1 were cultivated in calorie rich (left panels; SDC) or rapamycin (right panels; RM) medium and RNA was extracted and sequenced from exponential phase (top panels) or aging (bottom panels; 7 days after entry into quiescence) cells. $y$-axis: - $\log _{10}$ (p-value). $x$-axis: $\log _{2}\left(H P F 1\right.$ NA $\triangle$ /WA) - $\log _{2}(H P F 1$ NAWA $\triangle)$. Blue: transcripts more $(>2 x, p<0.05)$ abundant in HPF1 NAWA $\triangle$. Red: transcripts more $(>2 x, p<0.05)$ abundant in HPF1 NA $\triangle$ WA. The total number of transcripts passing each criterion are reported (top corners, blue and red text). Gene ontology classifications enriched among transcripts passing each criterion are indicated (blue and red arrows, table S5). (B) Comparing number of transcripts more $(>2 x, p<0.05)$ abundant in HPF1 NA/WA $\triangle$ (blue) or in HPF1 NAL/WA (red) across environments (SDC and RM, in exponential phase and after 7 days of aging (D7)). (C) Model for how WA-HPF1 shortens life span by shifting cells from a sedentary to a buoyant life style, exposing them to more oxygen, repressing lipid and purine biosynthesis and oxidizing free and protein bound methionine.

\section{DISCUSSION}

We found calorie restriction to delay chronological aging for each of the 1056 yeast genotypes studied. These overwhelmingly positive effect of calorie restriction is fully in line with reports on single gene knockouts, where calorie restriction extends chronological life span regardless of what gene is missing (Matecic et al. 2010). In contrast, calorie restriction only extends the replicative life span of approximately half of single gene knockouts, with many being negatively affected (Schleit et al. 2013). The diverging effects of calorie restriction on chronological and replicative life span may reflect the natural yeast life cycle; yeasts spend much time as starved, quiescent cells (Liti 2015) and survival in this state may be very strongly selected, but the aged, extensively replicated state is extremely rare and unlikely to be selected.

Chronological life span was extremely genotype dependent. Using genome-wide linkage analysis, we found a total of 30 distinct QTLs explaining up to $41 \%$ of life span variation. Among those, two major QTLs drove most of the life span variation ( 30\% and $\sim 20 \%)$, while the remaining QTLs were more time and environment specific and contributed less ( 3\% each). We linked the two major QTLs to the cell wall encoding genes FLO11 (chrlX) and HPF1 (chrXV), with West African (WA) alleles having a pronounced and dominant life span shortening effect. Cell wall proteins have previously been 
linked to yeast life span through their effect on cell wall integrity. The cell wall integrity pathway reacts to cell wall perturbations, induced by e.g. heat shock or starvation (Krause and Gray 2002), and regulates both chronological and replicative life spans (Kaeberlein and Guarente 2002; Matecic et al. 2010; Ray et al. 2003; Stewart et al. 2007). We found that the life span shortening induced by the WA-HPF1 was not by cell wall damage, but by a dramatic shift in life style. Cells carrying a North American (NA) HPF1 had long, sedentary lives in sedimented yeast populations, while cells carrying a WA-HPF1 lived shorter as buoyant, free-floating yeasts. The buoyancy was directly causing the shorter life span since enforcing a free-floating state of cells carrying the NA-HPF1, through vigorous shaking, shortened the life span to the same levels as that of cells carrying the WA-HPF1. We observed no strong buoyancy effect of FLO11 variation although FLO11 induced buoyancy has been previously reported (Fidalgo et al. 2006).

The reason why buoyancy shortens life span is likely by shifting cells from semi-anaerobic state within yeast sediments, to a highly oxygenated state while floating. Higher oxygen exposure means higher oxidative damage by reactive oxygen species, an oft-suggested explanation for life span shortening (Fabrizio et al. 2003; Longo et al. 1999). We found buoyant yeasts to broadly induce cellular systems dealing with methionine oxidation and depletion. Non-oxidized methionine is essential to the proper folding and function of proteins, synthesis of the central signalling molecule S-adenosine methionine and the maintenance of glutathione pools, a key redox buffer (Brown-Borg and Buffenstein 2017), helping to explain why buoyancy shortens life span. Rapamycin supplementation abolished the induction of the methionine oxidation response in buoyant yeasts, implying that rapamycin counters methionine oxidation and potentially explaining some of its life span extending effect. Buoyancy also broadly repressed lipid and purine biosynthesis genes. Both lipid and purine metabolisms have previously been linked to life span extension (Arlia-Ciommo et al. 2018; Matecic et al. 2010; Mohammad et al. 2018). Why this occurs in buoyant cells is unclear. It is possible that lipid and purine oxidation, caused by the excess load of reactive oxygen species in oxygen exposed buoyant yeasts, shortens life span by damaging membranes, signalling molecules and nucleotides. In addition, several studies connect methionine and lipid metabolisms, suggesting 
that early methionine perturbation during aerobic growth distorts lipid metabolism in aged cells (Hasek et al. 2013; Lee et al. 2014; Zhou et al. 2016).

HPF1 and FLO11, like the vast majority of genes encoding cell wall proteins, contain intragenic tandem repeats (Verstrepen et al. 2005). Intragenic tandem repeats are dynamic in size, both due to strand-slippage during replication and ectopic recombination (Fan and Chu 2007; Pâques, Leung, and Haber 1998), and were found to fuel rapid yeast evolution (Gemayel et al. 2012; Verstrepen et al. 2005). Here, we showed that expansion of the N-terminal intragenic repeats within WA-HPF1 was sufficient to shift yeasts towards a buoyant life style, which negatively impacted life span. The majority (14/21) of amino acids in the expanded $\mathrm{N}$-terminal repeat motif are serines or threonines, a huge overrepresentation compared to the $12 \%$ expected by their general prevalence in proteins (Kozlowski 2016). Serine and threonine are unique among amino acids in containing hydroxyl groups that directly facilitate hydrogen bonding with surrounding water molecules, an effect known to enhance the solubility of organic particles. An enticing possibility is therefore that the serine/threonine richness of the Hpf1p intragenic repeat expansion directly induces buoyancy. Furthermore, serine and threonine residues are highly O-glycosylated in the cell wall and in secreted proteins. Repeat expansion could thus increase cell wall glycosylation, which is predicted to improve solubility. In this model, the dynamic repeat expansions and contractions of HPF1 may serve as a life style switch, allowing rapid shifts between buoyant and sedentary life styles in evolution as dictated by fluctuating, opposing selection pressures. We note that the biochemical properties of the yeast cell wall have been linked to buoyancy (DeSousa et al. 2003; Fidalgo et al. 2006; Palmieri, Greenhalf, and Laluce 1996), albeit through hydrophobicity rather than by serine/threonine induced hydrogen bond formation with water molecules.

The HPF1 induced shift to a buoyant life style with concomitant life span shortening due to methionine, lipid and purine oxidation has no immediate parallel in multicellular organisms. Nevertheless, intragenic tandem repeats are enriched in human genes encoding extracellular proteins (Gemayel et al. 2010; Legendre et al. 2007). Mammalian cells maintain a complex 
bioRxiv preprint doi: https://doi.org/10.1101/653006; this version posted June 22, 2019. The copyright holder for this preprint (which was

not certified by peer review) is the author/funder, who has granted bioRxiv a license to display the preprint in perpetuity. It is made available under aCC-BY-NC-ND 4.0 International license.

relationship with the surrounding extracellular matrix. For instance, stem cell fate and proliferation are strongly determined by physical constraints, cellular shape, and environmental cues, including oxygen availability, through interactions with the surrounding matrix (Campisi 2001; Guilak et al. 2009; Rando 2006). The crosslinking theory of aging postulates that the progressive crosslinking of the extracellular matrix impairs tissue homeostasis and drives aging (Bjorksten 1968). Notably, fibroblast senescence can be reversed by culturing old cells in a young extracellular matrix (Choi et al. 2011). It is not inconceivable that intragenic repeat expansions also in human extracellular proteins modulate cell-matrix interactions with profound effects on cellular life span.

In a broader perspective, our understanding of the biological role of intragenic tandem repeats is still rudimentary. The study of the genotype-phenotype map has largely been limited to SNPs, CNVs and aneuploidies. Nonetheless, there is an increasing awareness that intragenic tandem repeat polymorphisms generate important functional variability. In addition to human neurodegenerative diseases such as Huntington's chorea or Fragile X syndrome (Gemayel et al. 2010; Orr and Zoghbi 2007), tandem repeat variations have been reported to drive the evolution of pathogenic bacteria (Stern et al. 1986), circadian clocks (Sawyer et al. 1997), and organismal morphology (Fondon and Garner 2004). Roughly, $17 \%$ of genes in the human genome contain intragenic tandem repeats (Legendre et al. 2007), and these are likely to have far-reaching effects on human biology. The ongoing development of long read sequencing will allow detecting intragenic repeat polymorphism and help uncover associations to many classes of phenotypic variation, as demonstrated in our study. 


\section{MATERIALS AND METHODS}

\section{Strains}

Phased Outbred Lines (POLs) were derived from a cross between a North American (NA) oak tree strain (YPS128) and a West African (WA) palm wine strain (DBVPG6044) (Liti et al. 2009). Heterothallic ancestral parents carrying LYS2 or URA3 at the LYS2 locus (Cubillos, Louis, and Liti 2009) were first mated to generate a pool of F1 hybrids. The pool was cycled through 12 rounds of alternating random mating, diploid selection, meiosis, sporulation, and haploid selection, resulting in a final pool of F12 outbred haploids (Parts et al. 2011). 86 F12 haploid segregants of each mating type were isolated, sequenced and their genotype was inferred using a set of 52466 markers (Illingworth et al. 2013). Phased Outbred Lines (POLs) were obtained as described (Hallin et al. 2016) with minor modifications. F12 segregants of opposite mating type were randomly paired and mated (YPD) in 96 well plates, and 1056 unique diploids with known, phased genomes were then selected during 3 consecutive diploid selective cultivations on minimal media. Diploids were arrayed, stored and analysed in 12x96 well plates, each plate containing 8 ( 3 each of NA/NA and WAVWA, and 2 of NA/WA) internal controls used for life span normalisation. Reciprocal hemizygotes at the HPF1 and FLO11 loci were constructed in a NA/WA diploid hybrid, using genetically tractable NA and WA haploids, as described (Cubillos, Louis, and Liti 2009). Native HPF1 and FLO11 genes were deleted in haploids by homologous recombination with a NatMX4 cassette, using the lithium acetate/PEG transformation protocol (Cubillos, Louis, and Liti 2009), before being mated to the appropriate counterpart to generate diploids hemi- or homozygote for HPF1 and FLO11. HPF1 allele swapping was performed in two steps. First, part of HPF1 (N-terminal repeats, C-terminal repeats, or internal part (Fig. 3C) was deleted in NA and WA haploids using homologous recombination with a URA3 cassette. Then, the HPF1 segments to be swapped were PCR amplified from the desired alleles with Platinum Superfi (Invitrogen) DNA polymerase and swapped into the orthologous position of the recipient strain using homologous recombination (targeting identical non-repeated sequences for both alleles) and selected on 5-FOA $1 \mathrm{~g} / \mathrm{L}$. Strains 
bioRxiv preprint doi: https://doi.org/10,1101/653006; this version posted June 22, 2019. The copyright holder for this preprint (which was

not certified by peer review) is the author/funder, who has granted bioRxiv a license to display the preprint in perpetuity. It is made available under aCC-BY-NC-ND 4.0 International license.

obtained were then mated to hpf1::NatMX4 haploids to generate the indicated diploids. Complete deletion of HPF1 in WA and NA diploids was performed in two consecutive transformation steps, replacing both copies with NatMX4 and KanMX4 cassettes.

A summary of strains and primers used in this study can be found in tables S1 and S2, respectively.

\section{Media}

YPD (1\% yeast extract, 2\% peptones, 2\% dextrose, 2\% agar (MP Biomedicals)) was used for all matings. Mated cells were streaked on synthetic minimal medium ( $2 \%$ dextrose, $0,675 \%$ yeast nitrogen bases (Formedium), $\mathrm{pH}$ set to 6.0 with $2.5 \mathrm{M} \mathrm{NaOH}$ ), to select for diploids. Life span was estimated in: i) calorie rich synthetic dextrose complete (SDC) media ( $2 \%$ dextrose, $0.675 \%$ yeast nitrogen base (Formedium), $0.088 \%$ complete amino acid supplement (Formedium), pH set to 6.0 with 2.5M NaOH), ii) calorie restricted (CR) media (SDC as above, but with $0,5 \%$ dextrose instead of 2\%) (Jiang 2000; Lin, Defossez, and Guarente 2000; Smith et al. 2007), and iii) rapamycin (RM) supplemented media (SDC supplemented with $0,025 \mu \mathrm{g} / \mathrm{mL}$ rapamycin (Sigma-Aldrich)) (Li et al. 2019; Vázquez-García et al. 2017).

\section{Chronological lifespan assay}

Cells cultivated overnight in calorie-rich (SDC) media were diluted (1:100) in $200 \mu \mathrm{L}$ of either fresh SDC, or $\mathrm{CR}$, or RM media in a 96 well plate. Cultivation plates were sealed with adhesive aluminium foil to prevent evaporation and incubated at $30^{\circ} \mathrm{C}$. Aging was considered to start at saturation of the culture, 72 hours post inoculation (Fabrizio and Longo 2007), and cells were kept in saturated media for the whole duration of the experiment unless otherwise specified. When CLS was performed in water (Fig. S4A only), 72 hours stationary cultures were centrifuged and cells were washed $3 x$ before being resuspended and kept in the same volume of distilled water.

Aging was measured as viable cells (\%) by flow cytometry based on the uptake of the fluorescent molecules propidium iodide (PI) and YO-PRO-1 iodide (YP). Propidium iodide and YO-PRO-1 are 
bioRxiv preprint doi: https://doi.org/10.1101/653006; this version posted June 22, 2019. The copyright holder for this preprint (which was

not certified by peer review) is the author/funder, who has granted bioRxiv a license to display the preprint in perpetuity. It is made available under aCC-BY-NC-ND 4.0 International license.

membrane-impermeable nucleic acid binding molecules that enter into necrotic but not into alive cells. Therefore, non-fluorescent cells are alive, while fluorescent cells are not. YO-PRO-1 penetrates also into apoptotic cells (Herker et al. 2004; Wlodkowic, Skommer, and Darzynkiewicz 2009). At each aging time point $(7,21,35$ days after entry into quiescence unless otherwise stated), $5 \mu \mathrm{L}$ of cells were transferred into $100 \mu \mathrm{L}$ of staining solution (Phosphate Buffer Saline $+3 \mu \mathrm{M}$ propidium iodide (Sigma) $+200 \mathrm{nM}$ YP (Invitrogen)) in a 96 well plate and incubated for $5 \mathrm{~min}$ in the dark at $30^{\circ} \mathrm{C}$. The samples were analysed on a FACS-Calibur flow cytometer (Becton Dickinson) using a High Throughput Sampler (Becton Dickinson) device to process 96 well plates and detect fluorescence with FL-1 (YP) and FL-3 (PI) channels. POLs experiments, where each allele is present and therefore replicated in many lineages, were run in single replicate and viability estimates were normalized to those of 8 internal controls run on the same plate. All other experiments were run at least in triplicates.

\section{Linkage analysis}

Linkage analysis was performed as described (Hallin et al. 2016). Briefly, mapping of life span QTLs was done using the normalized POL life spans, the R/qtl package in R (Broman et al. 2003), and the marker regression method in the scanone function. Significance thresholds were calculated with 1,000 permutations to call QTLs with a significance level of 0.05 . Confidence intervals for the peaks were calculated using a 1.8-LOD drop using the lodint function in R/qtl. We corrected for population structure by using the deviation of the lifespan of each POL from the parent mean.

\section{RNAseq}

We extracted RNA from SDC and RM cultivated cells in exponential phase and after 7 days of aging using the Kapa Biosystems hyperplus kit with Riboerase, as per user's instructions at 500nG input. RNA integrity was assessed on an Agilent Bioanalyzer using the RNA pico kit to determine RIN scores. Library quality was assessed using Agilent Bioanalyzer using the DNA 1000 Kit. Libraries 
bioRxiv preprint doi: https://doi.org/10.1101/653006; this version posted June 22, 2019. The copyright holder for this preprint (which was

not certified by peer review) is the author/funder, who has granted bioRxiv a license to display the preprint in perpetuity. It is made available under aCC-BY-NC-ND 4.0 International license.

were quantified using Kapa Biosystems library quantification kit. The libraries were normalized, pooled and loaded onto a NextSeq 500/550 High Output v2 kit (300 cycles) flow cell and sequenced on a Next seq 500 instrument. We performed transcript-level abundance quantification by pseudoaligning RNA-seq reads to the coding sequences of SGD yeast reference gene set, using Kallisto (v0.44.0) (Bray et al. 2016). In this way, we obtained the Transcripts Per Kilobase Million (TPM) value for each gene in each sample as its normalized expression level, which is directly comparable both among different genes and among different samples. Sleuth (0.30.0) (Pimentel et al. 2017) was further used to assess the statistical difference of the same gene between different samples by decoupling biological differences from experimental noise. False discovery rate (FDR; $\alpha=0.05$ ) adjustment (Benjamini and Hochberg 1995) was further applied for multiple test correction.

Total RNA was extracted from two biological replicates either during exponential growth or after 7 days of aging in SDC or in RM. Global expression level was analysed by pairwise comparison of the NA/WA hybrids hemizygotes for WA and NA-HPF1 within each environment and time point to identify differentially expressed transcripts.

Standard GO term analysis was performed on >2-fold differently expressed genes with the GO Term Finder tool available at SGD, with an FDR corrected $\alpha$ threshold of 0.01 .

Raw RNAseq reads are available at the NCBI Sequence Read Archive under accession PRJNA544860.

\section{Acknowledgments}

This work was supported by Agence Nationale de la Recherche (ANR-11-LABX-0028-01, ANR-13BSV6-0006-01, ANR-15-IDEX-01, ANR-16-CE12-0019 and ANR-18-CE12-0004) and the Swedish Research Council (2014-6547, 2014-4605 and 2018-03638). 


\section{REFERENCES}

Alvers, Ashley L. et al. 2009. "Autophagy and Amino Acid Homeostasis Are Required for Chronological Longevity in Saccharomyces Cerevisiae." Aging Cell 8(4): 353-69.

Arlia-Ciommo, Anthony et al. 2018. "Caloric Restriction Delays Yeast Chronological Aging by Remodeling Carbohydrate and Lipid Metabolism, Altering Peroxisomal and Mitochondrial Functionalities, and Postponing the Onsets of Apoptotic and Liponecrotic Modes of Regulated Cell Death." Oncotarget 9(22): 16163-84.

Benjamini, Yoav, and Yosef Hochberg. 1995. "Controlling the False Discovery Rate: A Parctical and Powerful Approach to Multiple Testing." Journal of the Royal Statistical Society. Series B 57(1): 289-300.

Bjorksten, Johan. 1968. "The Crosslinkage Theory of Aging." Journal of the American Geriatrics Society 16(4): 408-27.

Blagosklonny, Mikhail V. 2010. "Calorie Restriction: Decelerating MTOR-Driven Aging from Cells to Organisms (Including Humans)." Cell Cycle 9(4): 683-88.

Boer, V. M., S. Amini, and D. Botstein. 2008. "Influence of Genotype and Nutrition on Survival and Metabolism of Starving Yeast." Proceedings of the National Academy of Sciences 105(19): 6930-35.

Bray, Nicolas L., Harold Pimentel, Páll Melsted, and Lior Pachter. 2016. "Near-Optimal Probabilistic RNA-Seq Quantification." Nature Biotechnology 34(5): 525-27.

Brem, R. B. 2002. "Genetic Dissection of Transcriptional Regulation in Budding Yeast." Science. Broman, Karl W., Hao Wu, Śaunak Sen, and Gary A. Churchill. 2003. "R/Qtl: QTL Mapping in Experimental Crosses." Bioinformatics 19(7): 889-90.

Brown-Borg, Holly M., and Rochelle Buffenstein. 2017. "Cutting Back on the Essentials: Can Manipulating Intake of Specific Amino Acids Modulate Health and Lifespan?" Ageing Research Reviews.

Campisi, J. 2001. "From Cells to Organisms: Can We Learn about Aging from Cells in Culture?" Experimental Gerontology 36(4-6): 607-18.

Choi, Hae Ri et al. 2011. "Restoration of Senescent Human Diploid Fibroblasts by Modulation of the Extracellular Matrix." Aging Cell 10(1): 148-57.

Cohen, Brian D. et al. 2001. "Induction and Repression of DAN1 and the Family of Anaerobic 
Mannoprotein Genes in Saccharomyces Cerevisiae Occurs through a Complex Array of Regulatory Sites." Nucleic Acids Research 29(3): 799-808.

Colman, Ricki J et al. 2009. "Caloric Restriction Delays Disease Onset and Mortalilty in Rhesus Monkeys." Science 325(5937): 201-4.

Conti, Bruno et al. 2006. "Transgenic Mice with a Reduced Core Body Temperature Have an Increased Life Span." Science (New York, N.Y.) 314(5800): 821-25.

Cubillos, Francisco A., Edward J. Louis, and Gianni Liti. 2009. "Generation of a Large Set of Genetically Tractable Haploid and Diploid Saccharomyces Strains." FEMS Yeast Research 9(8): 1217-25.

DeSousa, Sandro R. et al. 2003. "Yeast Flotation Viewed as the Result of the Interplay of Supernatant Composition and Cell-Wall Hydrophobicity." Colloids and Surfaces B: Biointerfaces 29(4): 309-19.

Douglas, Lois M., Li Li, Yang Yang, and Anne M Dranginis. 2007. "Expression and Characterization of the Flocculin Flo11/Muc1, a Saccharomyces Cerevisiae Mannoprotein with Homotypic Properties of Adhesion." Eukaryotic Cell 6(12): 2214-21.

Eisenberg, Tobias et al. 2009. "Induction of Autophagy by Spermidine Promotes Longevity." Nature cell biology 11(11): 1305-14. http://dx.doi.org/10.1038/ncb1975.

Fabrizio, Paola et al. 2003. "SOD2 Functions Downstream of Sch9 to Extend Longevity in Yeast." Genetics 163(1): 35-46.

Fabrizio, Paola et al. 2010. "Genome-Wide Screen in Saccharomyces Cerevisiae Identifies Vacuolar Protein Sorting, Autophagy, Biosynthetic, and TRNA Methylation Genes Involved in Life Span Regulation." PLoS Genetics 6(7): 1-14.

Fabrizio, Paola, and Valter D. Longo. 2007. "The Chronological Life Span of Saccharomyces Cerevisiae." Methods in molecular biology (Clifton, N.J.) 371: 89-95.

Fan, Hao, and Jia You Chu. 2007. "A Brief Review of Short Tandem Repeat Mutation." Genomics, Proteomics and Bioinformatics 5(1): 7-14.

Fidalgo, M., R. R. Barrales, J. I. Ibeas, and J. Jimenez. 2006. "Adaptive Evolution by Mutations in the FLO11 Gene." Proceedings of the National Academy of Sciences 103(30): 11228-33. http://www.pnas.org/cgi/doi/10.1073/pnas.0601713103.

Finch, Caleb E. 1990. "Longevity, Senescence and the Genome." University of Chicago Press. 
Fondon, J. W., and H. R. Garner. 2004. "Molecular Origins of Rapid and Continuous Morphological Evolution." Proceedings of the National Academy of Sciences 101(52): 18058-63.

Garay, Erika et al. 2014. "High-Resolution Profiling of Stationary-Phase Survival Reveals Yeast Longevity Factors and Their Genetic Interactions." PLoS Genetics 10(2).

Gemayel, Rita, Janice Cho, Steven Boeynaems, and Kevin J. Verstrepen. 2012. "Beyond JunkVariable Tandem Repeats as Facilitators of Rapid Evolution of Regulatory and Coding Sequences." Genes 3(3): 461-80.

Gemayel, Rita, Marcelo D. Vinces, Matthieu Legendre, and Kevin J. Verstrepen. 2010. "Variable Tandem Repeats Accelerate Evolution of Coding and Regulatory Sequences." Annual Review of Genetics 44(1): 445-77.

Gomes, Pedro et al. 2007. "Low Auxotrophy-Complementing Amino Acid Concentrations Reduce Yeast Chronological Life Span." Mechanisms of Ageing and Development 128(5-6): 383-91.

Guilak, Farshid et al. 2009. "Control of Stem Cell Fate by Physical Interactions with the Extracellular Matrix." Cell Stem Cell 5(1): 17-26.

Guo, Bing, Cora A Styles, Qinghua Feng, and Gerald R Fink. 2000. "A Saccharomyces Gene Family Involved in Invasive Growth, Cell-Cell Adhesion, and Mating." Proceedings of the National Academy of Sciences of the United States of America 97(22): 12158-63. www.pnas.org.

De Haes, W. et al. 2014. "Metformin Promotes Lifespan through Mitohormesis via the Peroxiredoxin PRDX-2." Proceedings of the National Academy of Sciences 111(24): E2501-9. Hallin, Johan et al. 2016. "Powerful Decomposition of Complex Traits in a Diploid Model." Nature Communications 7: 13311.

http://www.nature.com/doifinder/10.1038/ncomms13311\%0Ahttp://biorxiv.org/lookup/doi/10. $1101 / 042176$.

Handee, Witawas et al. 2016. "An Energy-Independent Pro-Longevity Function of Triacylglycerol in Yeast." PLoS genetics.

Hansen, Malene et al. 2008. "A Role for Autophagy in the Extension of Lifespan by Dietary Restriction in C. Elegans." PLoS Genetics 4(2).

Harrison, David E. et al. 2009. "Rapamycin Fed Late in Life Extends Lifespan in Genetically Heterogeneous Mice." Nature. 
Hasek, Barbara E. et al. 2013. "Remodeling the Integration of Lipid Metabolism between Liver and Adipose Tissue by Dietary Methionine Restriction in Rats." Diabetes 62(10): 3362-72.

Herker, Eva et al. 2004. "Chronological Aging Leads to Apoptosis in Yeast.” Journal of Cell Biology 164(4): 501-7.

Illingworth, Christopher J.R. et al. 2013. "Inferring Genome-Wide Recombination Landscapes from Advanced Intercross Lines: Application to Yeast Crosses." PLoS ONE 8(5).

Jiang, J. C. 2000. "An Intervention Resembling Caloric Restriction Prolongs Life Span and Retards Aging in Yeast." The FASEB Journal.

Johnson, Thomas E. 1990. "Increased Life-Span of Age-1 Mutants in Caenorhabditis Elegans and Lower Gompertz Rate of Aging." Science 249: 908-9.

Jones, Owen R et al. 2014. "Diversity of Ageing across the Tree of Life." Nature 505(7482): 169-73.

Jung, Paul P. et al. 2018. "Natural Variation of Chronological Aging in the Saccharomyces

Cerevisiae Species Reveals Diet-Dependent Mechanisms of Life Span Control." Aging and Mechanisms of Disease 4(1).

Kaeberlein, Matt. 2014. "Rapamycin and Ageing: When, for How Long, and How Much?” Journal of Genetics and Genomics 41(9): 459-63.

Kaeberlein, Matt, and Leonard Guarente. 2002. "Saccharomyces Cerevisiae MPT5 and SSD1

Function in Parallel Pathways to Promote Cell Wall Integrity." Genetic Analysis 5(January): 8395.

Kenyon, Cynthia et al. 1993. "A C. Elegans Mutant That Lives Twice as Long as Wild Type.” Nature.

Kenyon, Cynthia. 2010. “The Genetics of Ageing." Nature 464(7288): 504-12.

Klass, Michael R. 1977. "Aging in the Nematode Caenorhabditis Elegans: Major Biological and Environmental Factors Influencing Life Span." Mechanisms of Ageing and Development 6(C): 413-29.

Kozlowski, Lukasz P. 2016. "Proteome-PI: Proteome Isoelectric Point Database." Nucleic Acids Research 45(D1): D1112-16.

Krause, Sue Ann, and Joseph V. Gray. 2002. "The Protein Kinase C Pathway Is Required for Viability in Quiescence in Saccharomyces Cerevisiae." Current Biology 12(7): 588-93.

Kwan, Elizabeth X. et al. 2013. "A Natural Polymorphism in RDNA Replication Origins Links Origin 
Activation with Calorie Restriction and Lifespan." PLoS Genetics 9(3).

Kwan, Elizabeth X., Eric Foss, Leonid Kruglyak, and Antonio Bedalov. 2011. "Natural

Polymorphism in Bul2 Links Cellular Amino Acid Availability with Chronological Aging and Telomere Maintenance in Yeast." PLoS Genetics.

Kwast, Kurt E, Patricia V Burke, Brett T Staahl, and Robert O Poyton. 1999. "Oxygen Sensing in Yeast: Evidence for the Involvement of the Respiratory Chain in Regulating the Transcription of a Subset of Hypoxic Genes." Proceedings of the National Academy of Sciences of the United States of America 96(10): 5446-51. www.pnas.org.

Lee, Byung Cheon et al. 2014. "Methionine Restriction Extends Lifespan of Drosophila Melanogaster under Conditions of Low Amino-Acid Status." Nature Communications 5. Legendre, Matthieu, Nathalie Pochet, Theodore Pak, and Kevin J. Verstrepen. 2007. "SequenceBased Estimation of Minisatellite and Microsatellite Repeat Variability." Genome Research 17(12): 1787-96.

Leiser, Scott F., Anisoara Begun, and Matt Kaeberlein. 2011. "HIF-1 Modulates Longevity and Healthspan in a Temperature-Dependent Manner." Aging Cell 10(2): 318-26.

Leiser, Scott F., Marissa Fletcher, Anisoara Begun, and Matt Kaeberlein. 2013. "Life-Span Extension from Hypoxia in Caenorhabditis Elegans Requires Both HIF-1 and DAF-16 and Is Antagonized by SKN-1." Journals of Gerontology - Series A Biological Sciences and Medical Sciences 68(10): 1135-44.

Li, Jing et al. 2019. "Shared Molecular Targets Confer Resistance over Short and Long Evolutionary Timescales" ed. Harmit Malik. Molecular Biology and Evolution.

Liao, Chen Yu et al. 2010. "Genetic Variation in the Murine Lifespan Response to Dietary Restriction: From Life Extension to Life Shortening." Aging Cell 9(1): 92-95.

Lin, S J, P A Defossez, and Leonard Guarente. 2000. "Requirement of NAD and SIR2 for Life-Span Extension by Calorie Restriction in Saccharomyces Cerevisiae." Science 289(5487): 2126-28.

Liti, Gianni et al. 2009. "Population Genomics of Domestic and Wild Yeasts." Nature 458(7236): 337-41.

Liti, Gianni. 2015. "The Fascinating and Secret Wild Life of the Budding Yeast S. Cerevisiae." eLife 4.

Longo, Valter D., Edith Butler Gralla, and Joan Selverstone Valentine. 1996. "Superoxide 
bioRxiv preprint doi: https://doi.org/10.1101/653006; this version posted June 22, 2019. The copyright holder for this preprint (which was not certified by peer review) is the author/funder, who has granted bioRxiv a license to display the preprint in perpetuity. It is made available under aCC-BY-NC-ND 4.0 International license.

Dismutase Activity Is Essential for Stationary Phase Survival in Saccharomyces Cerevisiae: Mitochondrial Production of Toxic Oxygen Species in Vivo." Journal of Biological Chemistry 271: $12275-80$.

Longo, Valter D., Lee Loung Liou, J S Valentine, and E B Gralla. 1999. "Mitochondrial Superoxide Decreases Yeast Survival in Stationary Phase." Archives of biochemistry and biophysics 365: $131-42$.

Longo, Valter D., Gerald S. Shadel, Matt Kaeberlein, and Brian K. Kennedy. 2012. "Replicative and Chronological Aging in Saccharomyces Cerevisiae." Cell Metabolism.

Lowry, C V, and R H Lieber. 1986. "Negative Regulation of the Saccharomyces Cerevisiae ANB1 Gene by Heme, as Mediated by the ROX1 Gene Product." Molecular and Cellular Biology 6(12): 4145-48.

Madia, Federica et al. 2008. "Longevity Mutation in SCH9 Prevents Recombination Errors and Premature Genomic Instability in a Werner/Bloom Model System." Journal of Cell Biology 180(1): 67-81.

Martin-Montalvo, Alejandro et al. 2013. "Metformin Improves Healthspan and Lifespan in Mice." Nature Communications 4.

Matecic, Mirela et al. 2010. "A Microarray-Based Genetic Screen for Yeast Chronological Aging Factors." PLoS genetics 6(4): e1000921.

Mattison, Julie A. et al. 2017. "Caloric Restriction Improves Health and Survival of Rhesus Monkeys." Nature Communications 8.

McCay, C. M., Mary F. Crowell, and L. A. Maynard. 1935. "The Effect of Retarded Growth Upon the Length of Life Span and Upon the Ultimate Body Size." The Journal of Nutrition 10(1): 6379.

Mohammad, Karamat et al. 2018. "Some Metabolites Act as Second Messengers in Yeast Chronological Aging." International Journal of Molecular Sciences 19(3).

Molin, Mikael et al. 2011. "Life Span Extension and H2O2 Resistance Elicited by Caloric Restriction Require the Peroxiredoxin Tsa1 in Saccharomyces Cerevisiae." Molecular Cell 43(5): 823-33.

Mortimer, RK, and JR Johnston. 1959. "Life Span of Individual Yeast Cells." Nature.

Orr, Harry T, and Huda Y Zoghbi. 2007. "Trinucleotide Repeat Disorders." Annual Review of Neuroscience 30: 575-623. 
Palmieri, M. C., W. Greenhalf, and C. Laluce. 1996. "Efficient Flotation of Yeast Cells Grown in Batch Culture." Biotechnology and Bioengineering 50(3): 248-56.

Pâques, Frédéric, Wai-Ying Leung, and James E. Haber. 1998. "Expansions and Contractions in a Tandem Repeat Induced by Double-Strand Break Repair." Molecular and Cellular Biology 18(4): 2045-54.

Parts, Leopold et al. 2011. "Revealing the Genetic Structure of a Trait by Sequencing a Population under Selection." Genome Research 21(7): 1131-38.

Peter, Jackson et al. 2018. "Genome Evolution across 1,011 Saccharomyces Cerevisiae Isolates." Nature.

Pimentel, Harold et al. 2017. "Differential Analysis of RNA-Seq Incorporating Quantification Uncertainty." Nature Methods 14(7): 687-90.

Pletcher, Scott D. et al. 2002. "Genome-Wide Transcript Profiles in Aging and Calorically Restricted Drosophila Melanogaster." Current Biology 12(9): 712-23.

Powers, R. Wilson et al. 2006. "Extension of Chronological Life Span in Yeast by Decreased TOR Pathway Signaling." Genes and Development 20(2): 174-84.

Rando, Thomas A. 2006. "Stem Cells, Ageing and the Quest for Immortality." Nature 441(7097): 1080-86.

Rascon, B., and J. F. Harrison. 2010. "Lifespan and Oxidative Stress Show a Non-Linear Response to Atmospheric Oxygen in Drosophila." Journal of Experimental Biology 213(20): 3441-48.

Ray, Alo et al. 2003. "Sir3p Phosphorylation by the SIt2p Pathway Effects Redistribution of Silencing Function and Shortened Lifespan." Nature Genetics 33(4): 522-26.

Sawyer, Lesley A et al. 1997. "Natural Variation in a Drosophila Clock Gene and Temperature Compensation." Science 278: 2117-20.

Schleit, Jennifer et al. 2013. "Molecular Mechanisms Underlying Genotype-Dependent Responses to Dietary Restriction." Aging cell.

Schulz, Tim J. et al. 2007. "Glucose Restriction Extends Caenorhabditis Elegans Life Span by Inducing Mitochondrial Respiration and Increasing Oxidative Stress." Cell Metabolism 6(4): 280-93.

Sestini, E A, J C Carlson, and R Allsopp. 1991. "The Effects of Ambient Temperature on Life Span, Lipid Peroxidation, Superoxide Dismutase, and Phospholipase A2 Activity in Drosophila 
Melanogaster." Experimental gerontology 26(4): 385-95.

Smith, Daniel L., Julie M. McClure, Mirela Matecic, and Jeffrey S. Smith. 2007. "Calorie Restriction Extends the Chronological Lifespan of Saccharomyces Cerevisiae Independently of the Sirtuins." Aging Cell 6(5): 649-62.

Steinkraus, K A, Matt Kaeberlein, and Brian K. Kennedy. 2008. "Replicative Aging in Yeast: The Means to the End." Annual review of cell and developmental biology 24: 29-54.

Steinmetz, Lars M. et al. 2002. "Dissecting the Architecture of a Quantitative Trait Locus in Yeast." Nature.

Stern, Anne, Melissa Brown, Peter Nickel, and Thomas F. Meyer. 1986. "Opacity Genes in Neisseria Gonorrhoeae: Control of Phase and Antigenic Variation." Cell 47(1): 61-71.

Stewart, Mark S., Sue Ann Krause, Josephine McGhie, and Joseph V. Gray. 2007. "Mpt5p, a Stress Tolerance- and Lifespan-Promoting PUF Protein in Saccharomyces Cerevisiae, Acts Upstream of the Cell Wall Integrity Pathway." Eukaryotic Cell 6(2): 262-70.

Stumpferl, Stefan W. et al. 2012. "Natural Genetic Variation in Yeast Longevity." Genome Research 22(10): 1963-73.

Sun, Jiayan et al. 1994. "Divergent Roles of RAS1 and RAS2 in Yeast Longevity." Journal of Biological Chemistry 269(28): 18638-45.

Váchová, Libuše et al. 2011. "Flo11p, Drug Efflux Pumps, and the Extracellular Matrix Cooperate to Form Biofilm Yeast Colonies." Journal of Cell Biology 194(5): 679-87.

Vázquez-García, Ignacio et al. 2017. "Clonal Heterogeneity Influences the Fate of New Adaptive Mutations." Cell Reports 21: 732-44.

Verstrepen, Kevin J., and Frans M. Klis. 2006. "Flocculation, Adhesion and Biofilm Formation in Yeasts." Molecular Microbiology 60(1): 5-15.

Verstrepen, Kevin J, An Jansen, Fran Lewitter, and Gerald R Fink. 2005. "Intragenic Tandem Repeats Generate Functional Variability." Nature genetics 37(9): 986-90.

Warringer, Jonas et al. 2011. "Trait Variation in Yeast Is Defined by Population History." PLoS Genetics 7(6).

Wei, Min et al. 2008. "Life Span Extension by Calorie Restriction Depends on Rim15 and Transcription Factors Downstream of Ras/PKA, Tor, and Sch9." PLoS genetics 4(1): e13. 
bioRxiv preprint doi: https://doi.org/10.1101/653006; this version posted June 22,2019 . The copyright holder for this preprint (which was

not certified by peer review) is the author/funder, who has granted bioRxiv a license to display the preprint in perpetuity. It is made available under aCC-BY-NC-ND 4.0 International license.

in Budding Yeast." PLOS ONE 2(8).

Weindruch, Richard, Roy L Walford, Suzanne Fligiel, and Anddonald Guthrie. 1986. "The

Retardation of Aging in Mice by Dietary Restriction: Longevity, Cancer, Immunity and Lifetime Energy Intake1." American Institute of Nutrition.

Wlodkowic, Donald, Joanna Skommer, and Zbigniew Darzynkiewicz. 2009. "Flow Cytometry-

Based Apoptosis Detection." Methods in molecular biology (Clifton, N.J.) 559: 19-32.

Yuan, Yiyuan et al. 2012. "Enhanced Energy Metabolism Contributes to the Extended Life Span of Calorie-Restricted Caenorhabditis Elegans.” Journal of Biological Chemistry 287(37): 3141426.

Yue, Jia Xing et al. 2017. "Contrasting Evolutionary Genome Dynamics between Domesticated and Wild Yeasts." Nature Genetics 49(6): 913-24.

Zhou, Xihong et al. 2016. "Methionine Restriction on Lipid Metabolism and Its Possible Mechanisms." Amino Acids 48(7): 1533-40. 